\title{
Ficción y realidad en la crónica de la fundación del convento de la Encar- nación de Lima
}

\section{Fiction and reality in the Chronicle of the Foundation of Encarnación's of Lima convent}

\author{
Martina Vinatea Recoba \\ Universidad del Pacífico \\ Lima, PERÚ \\ vinatea_rm@up.edu.pe
}

[Hipogrifo, (issn: 2328-1308), 1.2, 2013, pp. 125-133]

Recibido: 25-06-2013 / Aceptado: 30-07-2013

DOl: http://dx.doi.org/10.13035/H.2013.01.02.11

Resumen. Nuestro propósito es ver los límites entre la realidad y la ficción en los capítulos centrales del relato de la fundación del convento de la Encarnación de Lima realizado por el Padre Antonio de la Calancha. El convento fue fundado, en el año 1556, por doña Leonor de Portocarrero, y por doña Mencía de Sosa, su hija, viuda del traidor a la corona Francisco Hernández Girón. A pesar de que la crítica contemporánea considera las crónicas como un «género híbrido» entre la literatura y la historia, el relato del padre Calancha es básicamente histórico, y sigue el modelo de la historiografía humanista del siglo XVI, en el que se resalta el valor estético de la prosa con la finalidad de producir placer y contribuir en la interpretación.

Palabras clave. Crónica de Indias, Calancha, convento de Encarnación de Lima, Mencía de Sosa, historiografía humanista del siglo XVI.

Abstract. Our purpose is to study the limits between reality and fiction in the central chapters of the story of the foundation of the convento de la Encarnación of Lima by Father Antonio de la Calancha. The convent was founded in 1556 by Leonor de Portocarrero and her daughter Doña Mencía de Sosa, widow of the crown's traitor Francisco Hernández Girón. Despite the fact that the chronicles are consider a «hybrid genre» between literature and history by contemporary critics, Father Calancha's story is basically historic as it follows the model of humanist histography of the XVI century. We discuss that in this model aesthetic values are functional to the interpretation. 
Keywords. Indias's Chronicles, Calancha, Convento de la Encarnación of Lima, Mencía de Sosa, Humanist Histography of the XVI century.

Nuestro propósito es reflexionar acerca de la realidad y la ficción en los capítulos centrales del relato de la fundación del convento de la Encarnación de Lima realizado por el Padre Antonio de la Calancha en su Crónica moralizada del orden de San Agustín en el Perú, con sucesos ejemplares vistos en esta monarquía, Libro II, capítulos XXII-XXVI, Barcelona, Pedro Lacavallería, 1639. Es importante precisar que, aunque Calancha dedica cuatro capítulos a la fundación del convento que nos ocupa, nuestro artículo se centrará en dos de ellos, los capítulos XXII y XXIII.

Tal como asegura Rolena Adorno en su célebre artículo sobre las «Nuevas perspectivas de los estudios literarios coloniales»', uno de los problemas que han surgido en el intento de estos estudios de crear su propio sitio dentro del espacio selecto del canon literario hispánico es el de la relación entre realidad y ficción. Así la atribución de «vocación literaria» a los escritos históricos ha sido una constante en la investigación sobre la etapa colonial hispanoamericana: la crítica contemporánea considera las crónicas como un género «híbrido» entre la Historia y la Literatura². Sin embargo, consideramos que las ideas de González Echevarría sobre este punto son esclarecedoras: ${ }^{3}$ González asegura que el modelo de los cronistas era el de la historiografía humanista del siglo XVI, en la que se resaltaba el valor estético del acontecimiento que se narraba. Así los cronistas estaban obligados a organizar los hechos de modo coherente y armonioso con la finalidad de que produjeran placer y contribuyeran a la interpretación.

La representación de la realidad es verista, el cronista forma parte del relato, se hace presente en la historia que pretende narrar, aun cuando no haya sido testigo de los hechos que presenta. Herederos de la historiografía medieval, los cronistas de Indias presentan un relato lleno de descripciones de paisajes, del carácter de los hombres y una incidencia casi obsesiva en el providencialismo ${ }^{4}$.

González Echevarría afirma que el modelo historiográfico de los cronistas de Indias se caracteriza, en primer lugar, por el concepto providencialista de la historia: nada ocurre si no es por intermediación divina y todo obedece a un plan previsto desde el inicio de los tiempos. En segundo lugar, la elocuencia y el buen tono, que producen discursos elegantes. En tercer lugar, los dilemas morales están presentes, pero se enfatiza en la moral cortesana o caballeresca. Finalmente, el estilo de la prosa es elegante, retórico ${ }^{5}$. Las características mencionadas por Gonzáles Echevarría calzan perfectamente con la crónica moralizada de Calancha y nos permite abordar la crónica con mayor solvencia.

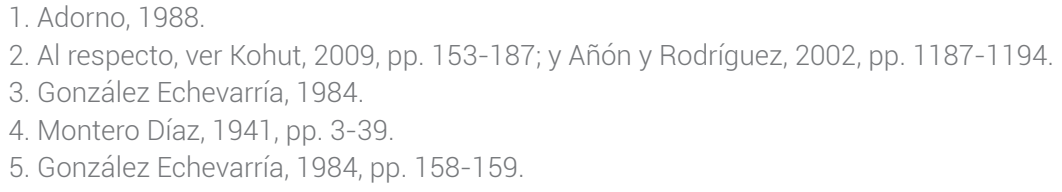




\section{EL AUTOR}

Fray Antonio de la Calancha, hijo del andaluz Francisco de la Calancha y de la criolla María Benavides, nació en 1584 en Chuquisaca, aunque algunos biógrafos afirman que fue en La Plata. Entra muy joven en la Orden de San Agustín, se doctora en Teología en la Universidad de San Marcos de Lima y llega a ser prior de su Orden. Fue también cronista de los agustinos, y por ello recorre gran parte del territorio peruano, donde recoge datos que lo ayudan a escribir su crónica. Asimismo, se le consideraba un buen predicador. El estilo de Calancha es descrito como abarrocado, incluso gongorino, permanentemente digresivo, y con un marcado afán por encontrar antecedentes bíblicos en todo lo que ocurrió en el Nuevo Mundo6.

\section{LA REALIDAD}

El Monasterio de la Encarnación de Lima fue el primer convento del Perú, fundado en el año 1556 por doña Leonor de Portocarrero y por doña Mencía de Sosa, su hija. El lugar elegido para la fundación fueron los predios de sus casas, cercanas a la Iglesia de San Sebastián, donde primero hicieron un beaterio, y luego el convento. El Virrey Marqués de Cañete y el Arzobispo fray Gerónimo de Loayza dieron la autorización para la fundación, pues las viudas manifestaron sus motivos: que estaban movidas por el deseo fervoroso de dedicarse al servicio de Dios y porque se sentían lastimadas por el

triste e ignominioso suceso del capitán Francisco Hernández Girón, marido de doña Mencía, el cual con color de defensa de la libertad del reino, inquietándole con guerras civiles fue ajusticiado por traidor y su cabeza puesta en el royo?.

Acompañaron a las dos señoras principales, doña Mariana de San Gerónimo, doña Inés Velásquez, doña Juana Girón, doña Juana Pacheco, doña María de la Cruz, doña Isabel de Alvarado y doña Inés de Mosquera.

Siguieron la Regla de San Agustín, y el Arzobispo nombró como priora a doña Leonor de Portocarrero, quien estuvo a cargo del monasterio por 28 años. Doña Mencía de Sosa la siguió y gobernó también por 28 años.

La fundación del convento de la Encarnación siguió la pauta de los conventos femeninos de toda la España Imperial: se convirtió en un reducto de mujeres pertenecientes a la nobleza local. También es conocida la valoración que se daba a la clausura de las mujeres en los conventos como salvaguarda de la honra. Al respecto, Mariló Vigil nos recuerda el modelo de la viuda: enlutada, doliente y enclaustrada ${ }^{8}$. Ángela Atienza llama especialmente la atención respecto de las condiciones de la fundación o patronato de un convento femenino y llama a muchas de las

6. Para los datos biográficos de Calancha, ver principalmente Benvenutto y Lohmann, 1938, pp. 13-14. También, Suárez Fernández, 1990, p. 413.

7. Cobo, 1882

8. Vigil, 1986, pp. 195-207. 
realizaciones conventuales del siglo XVII «fundaciones para sí mismas», pues fueron fundaciones impulsadas por mujeres que buscaron en ellas su propia conveniencia, sin desmedro de que estuviera también sustentada por una opción religiosa personal ${ }^{9}$. Así, para las viudas, el convento se convierte en el lugar ideal para el final de sus vidas, que ellas mismas organizan y donde podían mantener la preeminencia de la que gozaron cuando casadas. Asimismo, se rodearon de mujeres que pertenecían a su círculo social, muchas de estas mujeres fueron parientes que entraron como religiosas de velo negro sin llevar dote ni propina ni comida ni cera. De este modo, se aseguraban de que su entorno familiar estuviera presente en el claustro. Si se hace un recuento de las fundaciones, entre mediados del siglo XVI y mediados del siglo XVII, seis de los siete conventos limeños fueron fundados por viudas y por grupos familiares de mujeres que tenían las posibilidades y los recursos para procurarse un convento para su propio destino. Así, el convento de la Encarnación (1556) fue fundado por doña Mencía de Sosa, viuda de Francisco Hernández Girón, encomendero que se rebeló contra la corona y por doña Leonor de Portocarrero, viuda de Hernando Alonso de Almarás, tesorero de la Hacienda Real de Lima. El convento de la Concepción (1573) fue fundado por doña Inés de Muñoz, viuda del conquistador Martín de Alcántara (hermano menor de Francisco Pizarro), y por doña María de Chávez, viuda del hijo de doña Inés de Muñoz. El convento de la Santísima Trinidad (1579) fundado por doña Lucrecia de Sansoles, viuda de Hernando de Vargas, casada en segundas nupcias con Juan de Rivas, quien regresó al Perú procedente de La Paz para fundar el convento. El convento de las Concepcionistas descalzas (1603) fue fundado por doña Inés de Rivera y doña Beatriz de Horosco, hermanas del marqués de Mortara, quienes ya eran monjas en Chuquisaca, y doña María de Horosco quien influyó en las monjas antes mencionadas para que dejaran el convento en el que estaban y vinieran a Lima a fundar el nuevo convento de las Concepcionistas descalzas. El monasterio del Prado (1640) fue fundado por doña María de Poblete con la ayuda de doña Ángela de Zárate y Recalde, hermana del marqués de Valparaíso, la cual había sido abadesa del convento de la Encarnación ${ }^{10}$. El convento de las Carmelitas descalzas (1643) fundado por la dama milanesa Catalina María Doria, cuando queda viuda de don Domingo Gómez de Silva, encumbrado funcionario colonial ${ }^{11}$.

\section{LA FICCIÓN}

El padre Calancha dedica cinco capítulos del Libro II a la fundación del convento de la Encarnación, ocurrida, como ya se ha mencionado, en 1556.

El relato de Calancha dista temporalmente del acontecimiento en 83 años. Sin embargo, el Padre relata vívidamente, como si los hechos estuvieran ocurriendo frente a sus ojos. Probablemente, esta característica de su prosa se deba a que, tal como menciona Riva Agüero, el clérigo se nutrió de fuentes de distinto tipo que fue 
recogiendo a su paso por todo el virreinato peruano ${ }^{12}$, y a que -como buen historiador- Calancha daba importancia al estilo elegante construido con elocuencia y buen tono.

Veamos ahora cómo presenta los acontecimientos: «Capítulo XXII: De la fundación del celebrado convento de Nuestra Señora de la Encarnación, primer Monasterio de monjas el Perú, fundado por los religiosos de San Agustín, dícese su trágico principio, el trueque de prelados y los ejercicios de su primer asiento».

La primera idea presente en este capítulo está vinculada con la «predestinación» que, como afirma González Echevarría es la característica principal y primera de este tipo de relatos: «Inescrutables son los secretos del saber infinito de Dios». Luego, realiza una larguísima digresión respecto de cómo desde el inicio de nuestra historia, Dios prefigura un lugar cercado para las «verdaderas esposas de Cristo, el segundo Adán»:

Cría como advierte el decreto capítulo illud autem, distin. 40.i es de San Ambrosio, a nuestro padre Adán en el campo damasceno, donde ni lo cerca con tapias, ni lo encierra con cercas; y para criar a Eva lo lleva al paraíso cercado de murallas y guardando con defensas, allí se hizo el primer matrimonio, profecía del que Cristo hizo con la iglesia, ya se ve que fue decir, que las verdaderas esposas del segundo Adán, Cristo Nuestro Señor, son las que viven entre cercas y mueren entre clausuras $^{13}$.

Luego, presenta a las «flores» de jardín de Cristo, las monjas:

Adviértase que el mártir es flor del campo y en el campo puede crecer. La virgen es flor del jardín, ya porque Dios la estima en mucho más, y ya porque no estando encerrada en huerto, o crece poco o el aire la lastima, o la come, o pisa una bestia, estando expuesto a mil riesgos su valor y a varios peligros su hermosura ${ }^{14}$.

Sigue con la afirmación de que cada monja es «la reina que hace a Cristo rey» y que las reinas deben saber cómo deben atender a su esposo y cómo él las recompensará. Asimismo, indica cómo deben vestirse y el porqué de su hábito; cómo no deben dejarse tentar ni tocar por otras manos que no sean las divinas. Calancha sigue con los antecedentes y asegura que - según San Agustín- el primer convento de monjas fue de su orden y, por ello, corresponde a la Orden agustina tener el primer convento en el Perú:

El convento de la Encarnación fue la fértil parra, que dando a racimos siervas a Dios, y vírgenes a la Iglesia, repartió sarmientos fecundos en Lima, y a su imitación a todo este Perú, con que tiene Cristo no una esposa en su viña (como dice Salomón en los Cantares), sino viñas grandes cuajadas de esposas que salieron a plantar otros celestiales vidueños. Veamos este plantel fecundo y sabiendo los

12. Benvenutto y Lohmann, 1938, pp. 13-14.

13. Calancha, Crónica moralizada del orden de San Agustín, p. 420.

14. Calancha, Crónica moralizada del orden de San Agustín, p. 421. 
principios de su fundación, se verán los gloriosos aumentos de sus frutos, y las cosechas de sus soberanos esquilmos ${ }^{15}$.

En el capítulo XXIII titulado: En que se prosigue la materia misma y se refiere el principio de la fundación, después de cuatro páginas introductorias a la vida monacal, donde hace gala de un estilo elocuente, de buen tono, elegante y pleno de figuras retóricas, presenta por fin el inicio de la fundación conventual y por qué afirmaba al inicio que los secretos del Señor eran inescrutables: la vida de doña Mencía de Sosa fue un largo proceso de preparación para poder convertirse en «la capitana de los ejércitos de Dios». "Toda la dignidad de sus padres, las riquezas de sus maridos, y las prósperas y adversas fortunas de todos juntos, fueron disposiciones de la eterna providencia y medios de su predestinación, pues aun los pecados permitidos son antecedencias provechosas para los predestinados; dulce consuelo que da San Pablo a los pecadores penitentes» ${ }^{16}$. Casada con el capitán Francisco Hernández Girón, el traidor a la corona ${ }^{17}$, doña Mencía mostró ser el ejemplo de la perfecta casada. Tal como advierte González Echevarría, se presentan dilemas morales que se resuelven al estilo cortesano o caballeresco: doña Mencía debe elegir entre la lealtad al rey o a su marido y responde a la altura de las circunstancias: su lealtad primera debe ser hacia su marido. Así, cual heroína de relato medieval, Mencía de Sosa representa el ideal de la perfecta casada y sigue a su marido, aun cuando esta situación le acarrea sufrimientos, pobrezas y oprobio. Después de muerto el marido, ella mantiene ese ideal de perfecta casada, pero esta vez acierta con el «objeto de su afecto», pues se convierte en la esposa del mejor, de Cristo. El relato que presenta Calancha pareciera el de un biógrafo que vio «con sus propios ojos» los acontecimientos de la vida de doña Mencía. Esta toma de perspectiva, le permite a Calancha un juego con el tiempo y en la memoria y así alcanzar los valores dramáticos necesarios para conseguir el grado de verosimilitud necesario para el relato ${ }^{18}$.

[Hernández Girón] «envió a rogar a su mujer doña Mencía de Sosa con Gonzalo Vásquez y un religioso de la merced, se quisiese quedar, porque sin estorbo el pudiese ir [a las guerras civiles]. Mostró recibir gran pena, diciendo que pues Francisco Hernández Girón la había sacado de casa de sus padres, y la había (hasta entonces) traído en su compañía, no quería sino seguirle, y serle compañera en todos sus trabajos, como lo había sido en las honras y prosperidades, y que cuando su marido no quisiese por amor, lo había de conceder por fuerza, porque con un bordón y a pie le había de seguir, sin que trabajos ni dificultades le obligasen a dejar, valiente ánimo de mujer, y ejemplo singular de perfecta casada. Sabida por

15. Calancha, Crónica moralizada del orden de San Aqustín, p. 423

16. Calancha, Crónica moralizada del orden de San Agustín, p. 425

17. Para la información sobre Hernández Girón, ver Varallanos, 1959, p. 255 y Vinatea, 2009, pp. 127129 .

18. Recordemos que en el Fedro, Platón - admirado por San Agustín y, por ello, favorito de los agustinos- exige que se cumpla el principio de la verosimilitud para lograr la apariencia de vida: «He oído decir con este motivo, mi querido Sócrates, que el que ha de ser orador no necesita saber lo que es verdaderamente cierto, sino lo que parece tal a la multitud encargada de decidir; ni tampoco lo que es verdaderamente bueno y bello, sino lo que tiene las apariencias de la bondad y de la belleza. Porque es la verosimilitud, no la verdad, la que produce la convicción». Platón, Obras completas, p. 312. 
Girón la respuesta, entró a su tienda y le dijo: «Nunca Dios tal quiera Señora, que os deje yo, no siendo vuestra voluntad, por tanto aparejaos y seguidme». Al punto, doña Mencía mandó aparejar sus líos, y componer sus cargas, dando prisa a sus criados para que fuesen delante en el carruaje, sin dejar cosas de su ropa y cama.

Luego que partió la recámara de esta señora, comenzó una común murmuración de los soldados, de querer su general (cuando había de ir sin estorbos) llevar mujer. Conoció Girón el enfado de su ejército, y pospuso el amor de su esposa (no sé si movido de amor proprio o deseoso de las comodidades de su mujer) diciéndole el daño que le vendría de su llevada, y las conveniencias de quedarse, se despidió quebrantado de dolor y ella cayó desmayada de pena. Cuando volvió del desmayo, preguntó por su marido, dijéronle su fuga, levantóse acelerada, contentándose con solo verle (arrobos del amor y accidentales paladeos de la voluntad) subióse a un alto para poderlo divisar, no pudo, porque ya no le podía descubrir (finezas de noble, y afectos de honrada) bajó y disimulando el dolor esforzó cuanto pudo a los capitanes a que siguiesen a su esposo, queriendo más su defensa que su propio amparo (valor nuevo en estos tiempos desconcertados, ensayez para capitana en el ejército de Dios) donde se quedó con el oficio, trocando la intención y el motivo. Quedó sola y tan pobre que una camisa no le quedaba, ni un criado le servía, porque pensando acompañar a su esposo, quedó sin alhaja. ¡Oh trazas de Dios que dispone unos medios tan distantes para unos fines tan convenientes! Trujo a doña Mencía el capitán Ruibarba al Cuzco, amparóla el oidor Saravia, su compadre y del Cuzco (con todo respeto y estimación) la trajeron a Lima a casa de sus padres, donde ocupada en penitencias estaba en extraño retiro y virtuosa clausura. Llevó con gran valor y cristiano pecho el triste espectáculo que le pasaban arrastrando en un serón a la cola de un caballo (afrentoso castigo) al marido que tanto estimó, oyendo a su esquina este lastimoso pregón. Esta es la justicia que manda hacer su majestad, y el magnífico caballero Pedro Puertocarrero, maestre de campo, a este hombre por traidor a la corona, e alborotador de estos reinos, mándale cortar la cabeza por ello, y fijarla en el royo de esta ciudad, y que sus casas sean derribadas y sembradas de sal y puestos en ellas un mármol, con un rótulo que declare su delito. Quien supo de solo oír la despedida de su marido, quedó grande rato desmayada, con quedarle esperanza de volverlo a ver, tuviera por sin duda que se muriera, o la desmayara el dolor, cuando oía de su marido deshonras, muerte y apartamento tan lastimoso. Pero tenía ya otro esposo en la consideración y otro valor en el ánimo. Volviose a un Cristo, y dijo: «Hágase en todo tu voluntad, recibe este dolor que traspasa mi ánima, y ponlo entre los que atormentaron tu cuerpo santísimo, y gane por ellos que mi esposo muera en tu gracia y yo quede en tu amparo, que desde hoy no querré otro esposo, y en mi vida solo pretenderé tu amor» ${ }^{19}$.

Como podemos ver en este fragmento, pareciera que el modelo del relato fueran las Heroidas de Ovidio, pues centra la historia de Mencía de Sosa en su humanidad y su reacción ante el abandono de su marido. Debe recordarse que la traducción de la obra de Ovidio circuló entusiastamente en toda la América colonial, gracias a la traducción que Diego Mexía de Fernangil hiciera en 1608.

También cabe precisar que Calancha narra la historia de doña Mencía como si hubiese sido testigo presencial de los hechos. Es más, como si hubiera sido su

19. Calancha, Crónica moralizada del orden de San Agustín, pp. 424-425. 
propia conciencia. Narrador omnisciente, introduce discursos directos, flujos de conciencia. También comenta y alaba en medio de la narración de hechos aparentemente reales. Los comentarios realizados por Calancha: «Valiente ánimo de mujer y ejemplo de perfecta casada», «finezas de noble, y afectos de honrada», «valor nuevo en estos tiempos desconcertados», «ensayez para capitana en el ejército de Dios», «iOh trazas de Dios que dispone unos medios tan distantes para unos fines tan convenientes!», introducidos como discurso directo en el relato, muestran una suerte de identificación entre el autor y la «heroína» de su crónica. Asimismo, muestra lo que ha logrado plasmar entre los datos que había recogido de doña Mencía (que podrían haber derivado en una descripción estática) y la presentación de los mismos de manera dinámica.

\section{CONCLUSIONES}

A pesar de que la crítica contemporánea considera las crónicas como un «género híbrido» entre la Literatura y la Historia y, aunque quisiéramos que la balanza se inclinara más hacia la Literatura, el relato del padre Calancha es básicamente histórico y sigue el modelo de la historiografía humanista del siglo XVI, en la que - siguiendo a González Echevarría - se resalta el valor estético con la finalidad de producir placer y contribuir en la interpretación. Asimismo, sigue las características del mencionado modelo historiográfico: incide en el concepto providencialista: Dios previó los cenobios desde el inicio de los tiempos y en el Nuevo Mundo no podían faltar. Todo aquello que ocurre en la vida de doña Mencía de Sosa forma parte de un plan divino. Ella resuelve un dilema moral y lo hace de la mejor manera: sigue a su marido. Representa el ideal de esposa perfecta que le permitirá luego ser la mejor esposa de Cristo y capitana de sus ejércitos.

La elocuencia, el buen tono y el estilo elegante y retórico iluminan un texto que de otra manera habría pasado desapercibido entre la gran cantidad de crónicas de Indias.

\section{BIBLIOGRAFÍA}

Adorno, Rolena, «Nuevas perspectivas en los estudios coloniales hispanoamericanos», Revista de crítica literaria latinoamericana, 14, 28, Historia, Sujeto social y discurso poético en la colonia, 1988, pp. 11-28.

Añón, Valeria y Jimena Rodríguez, «¿Crónicas, historias o relatos de viaje?», en Acerca de los nuevos estudios coloniales latinoamericanos, VII Congreso Internacional Orbis Tertius de Teoría y Crítica Literaria, La Plata, Orbis Tertius, 2009. Disponible en línea:

http://viicitclot.fahce.unlp.edu.ar/actas-del-vii-congreso-internacional-orbis-tertius-1/actas-del-vii-congreso-internacional-orbis-tertius-1/ponencias/AnonRodriguez.pdf

Atienza López, Ángela, Tiempo de conventos, Madrid, Marcial Pons, 2008. 
Benvenutto, Pedro y Guillermo Lohmann, Los cronistas de convento, Paris, Desclée de Brouwer, 1938.

Calancha, Antonio de la, Crónica moralizada del orden de San Agustín en el Perú, con sucesos ejemplares vistos en esta monarquía, libro II, caps. XXII-XXVI, Barcelona, Pedro Lacavallería, 1639.

Cobo, Bernabé, Historia de la fundación de Lima, ed. Manuel González la Rosa, Lima, Imprenta liberal, 1882.

González Echevarría, Roberto, «Humanismo, retórica y las crónicas de Indias», en Historia y ficción en la narrativa hispanoamericana, Caracas, Monte Ávila, 1984, pp. 149-166.

Guerra, Margarita, et al., La mujer en la conquista y la evangelización en el Perú, Lima, Fondo editorial de la Pontificia Universidad Católica del Perú, 1997.

Kohut, Karl, «Las primeras crónicas de Indias y la teoría historiográfica», Colonial Latin American Review, 18, 2, 2009, pp. 153-187.

López de Mariscal, Blanca, «La relación entre imaginario y referente en los relatos de viaje al Nuevo Mundo en el siglo XVI», en Memoria de la palabra: Actas del VI Congreso de la Asociación Internacional Siglo de Oro, Burgos-La Rioja, 1519 de julio de 2002, coord. Francisco Domínguez Matito y María Luisa Lobato Madrid, Iberoamericana, 2004, vol. II, pp. 1187-1194.

Mexía Fernangil, Diego, Primera parte del Parnaso Antártico, Sevilla, Alonso Rodríguez, 1608.

Montero Díaz, Santiago, «La doctrina de la Historia en los tratadistas españoles del Siglo de Oro», Madrid, 1939 (Hispania, IV, 1941, pp. 3-39) [Conferencia pronunciada en la Facultad de Filosofía y Letras en el año académico 1939-1940].

Platón, Obras completas, ed. Patricio de Azcárate, vol. II, Madrid, 1871.

Suárez Fernández, Luis, Historia general de España y América, vol. IX, Madrid, RIALP, 1990.

Varallanos, José, Historia de Huánuco, Buenos Aires, Imprenta López, 1959.

Vigil, Mariló, La vida de las mujeres en los siglos XVI y XVII, Madrid, Siglo XXI, 1986, pp. 195-207.

Vinatea Recoba, Martina, ed., Epístola de Amarilis a Belardo, Madrid, Iberoamericana/Vervuert, 2009.

- «Catalina María Doria, fundadora del convento de las Carmelitas descalzas de Lima», en La clausura femenina en el mundo hispánico: una fidelidad secular, Madrid, Estudios Superiores del Escorial, 2011, pp. 1147-1157. 
